\section{Efecto antibacteriano de Psidium guajava L y Psidium acutangulum Mart sobre Streptococcus mutans}

\section{Antibacterial effect of Psidium guajava $\mathrm{L}$ and Psidium acutangulum Mart on Streptococcus mutans}

\begin{abstract}
Resumen
Objetivo: Evaluar el efecto antibacteriano in vitro de los extractos de Psidium guajava $\mathrm{L}$ (P. guajava) y Psidium acutangulum Mart. ex DC (P. acutangulum) sobre cepas aisladas de Streptococcus mutans (S. mutans) y la cepa control ATCC 25175. Métodos: Los extractos se obtuvieron de frutos sanos y frescos de guayaba en su estado verde y maduro de las especies mencionadas. La identificación de $S$. mutans a partir de muestras de pacientes con caries cavitadas (código 5 según ICDAS) y de la cepa control se realizó mediante la siembra en agar Mitis Salivarius, en condiciones de anaerobiosis, a $37^{\circ} \mathrm{C}$, durante 48 horas, observándose colonias azules, rugosas, y las pruebas de susceptibilidad se realizaron mediante el método de difusión en disco con los extractos obtenidos. Resultados: $S$. mutans fue sensible al extracto de las cáscaras de $P$. guajava en estadio verde, tanto para la cepa control, como para la cepa del paciente, observándose el mayor halo para $S$. mutans ATCC 25175, reportándose un porcentaje de inhibición de 43,8\%. Conclusiones: Los extractos de las cáscaras de $P$. acutangulum y $P$. guajava tienen efecto antibacteriano sobre $S$. mutans, representando una opción alternativa frente a este microorganismo, siendo un posible producto complementario a la prevención del desarrollo de la caries dental.
\end{abstract}

Palabras clave: Antibacterianos; Caries dental; Extractos vegetales; Psidium; Streptococcus mutans.

\begin{abstract}
Objective: To evaluate the in vitro antibacterial effect of Psidium guajava L. (P. guajava) and Psidium acutangulum Mart. ex DC (P. acutangulum) extracts on isolated strains of Streptococcus mutans and control strain ATCC 25175. Methods: The extracts were obtained from healthy and fresh guava fruits in their green and mature state of the mentioned species. The identification of $S$. mutans from samples of patients with cavitated caries lesions (code 5, ICDAS) and from the control strain was carried out on Mitis Salivarius agar, under conditions of anaerobiosis, at $37^{\circ} \mathrm{C}$, for 48 hours, observing blue, rough colonies, and susceptibility tests were carried out using the disc diffusion method with the extracts obtained. Results: $S$. mutans was sensitive to the $P$. guajava extract, both for the control strain and for the patient strain, observing the highest inhibition halo for $S$. mutans ATCC 25175, reporting 43.8\% of inhibition. Conclusions: The extracts of the $P$.
\end{abstract}

\section{Artículo Original}

\author{
Josmary Afonso 1,a, Aurimar García 1,a, Johanna \\ Golindano ${ }^{1, a}$, Julia Sleiman 1,a, Andreína Fer- \\ nandes $2, b$
1 Universidad Central de Venezuela, Facultad de Odontología. Caracas, Venezuela.
2 Universidad Central de Venezuela, Facultad de Odontología, Instituto de Investigaciones Odon- tológicas "Raúl Vincentelli”. Caracas, Venezuela. a Estudiante de Odontología. \\ ${ }^{\mathrm{b}}$ Doctora en Ciencias. \\ Correspondencia: \\ Andreína Fernandes \\ Correo electrónico: \\ andreinafernandesb@gmail.com \\ Universidad Central de Venezuela, Facultad de \\ Odontología, Instituto de Investigaciones "Raúl \\ Vincentelli". Ciudad Universitaria, Los Chagua-
} ramos, Caracas, Venezuela.

\section{Coautores: \\ Josmary Afonso \\ josmary777@gmail.com \\ Aurimar García \\ aurimaragarciap@gmail.com \\ Johanna Golindano \\ johanna.gobra@gmail.com \\ Julia Sleiman \\ julia_rebeca9@hotmail.com}

Conflicto de intereses: Los autores declaran no tener conflictos de interés.

Fuente de financiamiento: Autofinanciado

Fecha de recepción: 16/04/18

Fecha de aceptación: 13/08/18

( ) Los autores. Este artículo es publicado por la revista Odontología Sanmarquina de la Facultad de Odontología, Universidad Nacional Mayor de San Marcos. Este es un artículo de acceso abierto, distribuido bajo los términos de la licencia Creative Commons Atribucion - No Comercia_Compartir Igual 4.0 Internacional. (http://creativecommons.org/licenses/by-nc-sa/4.0/) que permite el uso no comercial, distribución y reproducción en cualquier medio, siempre que la obra original sea debidamente citada. 
acutangulum and $P$. guajava husks have antibacterial effect on $S$. mutans, representing an alternative option against this microorganism, being a possible complementary product to the prevention of the development of dental caries.

Keywords: Anti-bacterial agents; Dental caries; Plant extracts; Psidium; Streptococcus mutans.

\section{Introducción}

La caries dental es un proceso dinámico de desmineralización y remineralización del esmalte, producto del metabolismo bacteriano sobre la superficie dentaria, que con el tiempo puede producir una pérdida neta de minerales y posiblemente, aunque no siempre, resultará en la presencia de una cavidad ${ }^{1}$.

Es el padecimiento de mayor prevalencia y costo a nivel mundial, estimándose que tiene una incidencia cercana al $70 \%$ en la población en general, presentándose con mayor frecuencia en países en vías de desarrollo, con poco acceso a las prácticas de higiene bucal. Suele aparecer en los niños, pero puede afectar a cualquier persona y es la causa más importante de pérdida de los dientes en las personas más jóvenes ${ }^{2}$.

La prevalencia de caries dental en Venezuela ha ido aumentando debido a la situación económica que atraviesa actualmente el país y por lo tanto, la salud bucal de la población ha empeorado considerablemente por la falta de productos básicos para la higiene bucal ${ }^{3}$.

Streptococcus mutans (S. mutans) es un coco Gram positivo, anaerobio facultativo, que en base a las pruebas bioquímicas, se caracteriza por ser inmóvil, negativo para la enzima catalasa, formador de ácido láctico con capacidad de variar el pH del medio de 7 a 4,2 en aproximadamente 24 horas. Por lo general son cepas no hemolíticas en agar sangre, siendo principalmente alfa o gamma hemolítico en este medio, aunque se han reportado unas pocas cepas hemolíticas ${ }^{4}$.

Gracias a su capacidad de sintetizar glucanos, fijar compuestos y ajustar su aciduricidad, $S$. mutans muestra un tropismo específico por la biopelícula dental, siendo la superficie del diente su hábitat natural. A través de mecanismos de señalización del quorum sensing, como la respuesta de tolerancia al ácido (RTA) dependiente de la densidad celular, $S$. mutans se ha adaptado para lograr su supervivencia y persistencia en la cavidad bucal ${ }^{1}$.

S. mutans es capaz de metabolizar la sacarosa, la glucosa y la fructosa, carbohidratos fermentables, ocasionando la producción de ácido láctico, ácido propiónico, ácido acético y ácido fórmico, los cuales son capaces de circular desde la biopelícula dental hacia el esmalte poroso del diente, generando la liberación de hidrogeniones a partir de su disociación. Estos hidrogeniones promueven la disolución rápida del esmalte, formando calcio y fosfato, los cuales difunden fuera del mismo, ocasionando un proceso de desmineralización ${ }^{3}$.

La caries dental es una enfermedad multifactorial, por lo que una sola herramienta preventiva no puede eli- minar completamente la enfermedad ${ }^{2}$. Actualmente, se ha promovido el uso de plantas medicinales en nuestro medio, debido a que en gran cantidad de vegetales se encuentran principios activos empleados en el tratamiento de diversas enfermedades. Según la Organización Mundial de la Salud (OMS) cerca del 80\% de la población mundial utilizan medicinas tradicionales en el tratamiento de problemas de salud ${ }^{5}$. Diversos estudios han demostrado que extractos de plantas superiores muestran una buena actividad antimicrobiana, siendo blanco de estudio para el desarrollo de medicina alternativa con base científica ${ }^{6}$.

Recientemente se han reportado trabajos donde muestran que especies de guayaba tienen propiedades antimicrobianas, frente a diversos microorganismos comúnmente encontradas en la cavidad bucal ${ }^{7}$. Extractos de especies de guayaba como Psidium guajava L. (P. guajava) y Psidium guineense $\mathrm{Sw}$ (P. guineense) fueron obtenidos tanto de las hojas ${ }^{8-11}$, como de las cáscaras, reportando actividad antimicrobiana frente a cepas de S. mutans ${ }^{8-10}$, así como otros microorganismos como Escherichia coli (E. coli) ${ }^{9,11}$, Salmonella enteritidis (S. enteritidis) ${ }^{9}$, Staphylococcus aureus (S. aureus) ${ }^{9,11}$, Bacillus cereus (B. cereus) ${ }^{9}$, Pseudomonas aeruginosa (P. aeruginosa) ${ }^{11}$, Aspergillus niger (A. niger) y Candida albicans (C. albicans) ${ }^{11}$.

Por esta razón, la elaboración de extractos de guayaba con efectos antibacterianos en el ámbito clínico, podrían ser utilizados como una alternativa en la prevención y tratamiento de la caries dental, con posibilidades de éxito, un reducido valor económico y bajo índice de toxicidad para el organismo. Es por ello que el objetivo del presente trabajo fue evaluar el efecto de los extractos de guayaba frente a las cepas de $S$. mutans, principal causante de la enfermedad bucal más prevalente en la población en general, como lo es la caries dental.

\section{Métodos}

Tipo y diseño de la investigación. Descriptivo, experimental, in vitro.

Material vegetal. Se contaron con frutos sanos y frescos de guayaba en su estado verde y maduro de las especies P. guajava y Psidium acutangulum Mart. ex DC (P. acutangulum). La primera especie $P$. guajava, recolectada en Terrazas de Vista Alegre, Calle Terepaima, Quinta Aina, Parroquia el Paraíso en Caracas. Mientras que la segunda, P. acutangulum, recolectada en el Parque Generalísimo Francisco de Miranda. Av. Francisco de Miranda, Los Palos Grandes. Estado Miranda. Ambas identificadas por el Herbario Dr. Víctor Manuel Ovalles, pertene- 
ciente a la Facultad de Farmacia de la Universidad Central de Venezuela, bajo el número de folio MYF29365.

Obtención del extracto vegetal. La pulpa de cada especie de guayaba, tanto verde, como madura, fue removida para obtener las cáscaras de las mismas. Se pesaron $4,8 \mathrm{~g}$ de cada una y fueron colocadas en estufa, a $45^{\circ} \mathrm{C}$ durante 24 horas, para secarlas completamente. Seguidamente, fueron pulverizadas y posteriormente maceradas con $50 \mathrm{~mL}$ de etanol al $100 \%$, durante 5 días. Se procedió a filtrar el contenido con el uso de un embudo y papel de filtro de $0,2 \mu \mathrm{m}$. El filtrado se recuperó en un vaso de precipitado estéril y se colocó nuevamente en estufa a $45^{\circ} \mathrm{C}$, hasta sequedad. Los extractos puros fueron resuspendidos con $50 \mathrm{~mL}$ de agua destilada para ser utilizados sobre los medios de cultivo correspondientes, para una concentración final de $96 \mathrm{mg} / \mathrm{mL}$, modificado de Neira y Ramírez ${ }^{8}$ y Limsong et al. ${ }^{12}$.

Los extractos fueron almacenados a $4{ }^{\circ} \mathrm{C}$ hasta su uso. Este procedimiento se realizó en el Centro de Biotecnología Aplicada a la Odontología (CEBAO), del Instituto de Investigaciones Odontológicas "Raul Vincentelli", de la Facultad de Odontología, de la Universidad Central de Venezuela.

Microorganismos. Cepa Control: se utilizó la cepa de S. mutans ATCC 25175, adquirida en el Centro Venezolano de Colección de Microorganismos (CVCM) del Instituto de Biología Experimental (IBE). El cultivo se realizó en agar Sangre (OXOID, UK) y Mitis Salivarius (OXOID, UK), a $37^{\circ} \mathrm{C}$, bajo condiciones de anaerobiosis, durante 48 horas.

Cepas del estudio: se aislaron cepas de $S$. mutans de tres pacientes pediátricos que presentaron lesiones de caries cavitadas activas (código 5 según ICDAS), atendidos en la sala clínica de Odontopediatría de la Facultad de Odontología de la Universidad Central de Venezuela y que no consumieron antibióticos previamente (2 meses). A cada paciente se le realizó un examen clínico completo, con espejo y sonda periodontal. Su representante firmó, previamente a la recolección, el consentimiento informado correspondiente a la sala clínica donde se tomaron las muestras.

Para la recolección de las muestras, se secó la superficie del diente, se aisló relativamente el área con algodones, se introdujo la punta del explorador estéril y se realizó un raspado de la zona afectada. El material obtenido, se resuspendió en un tubo Eppendorf de 1,5 mL con caldo nutritivo. Las muestras fueron llevadas al Laboratorio de Microbiología “Dr. Vicente Martínez Escarbassiere”, del Instituto de Investigaciones Odontológicas "Raúl Vincentelli", donde fueron sembradas en agar Sangre y agar Mitis Salivarius, a $37^{\circ} \mathrm{C}$, bajo condiciones de anaerobiosis, durante 48 horas. Se consideraron colonias positivas para $S$. mutans aquellas que presentaron alfa y gamma hemólisis en agar Sangre, y colonias azules, rugosas, en Mitis Salivairus, gracias al azul de tripano. El crecimiento de las colonias sugestivas en los medios selectivos fue comparado con el crecimiento de la cepa control.
Tinción de Gram. Bajo condiciones de esterilidad, se colocó una gota de agua destilada sobre un portaobjetos. Se tomó una colonia aislada sugestiva de $S$. mutans de los medios de cultivo, con el asa de platino y se mezcló suavemente con la gota de agua. Se dejó secar a temperatura ambiente. Se realizó la coloración correspondiente y se examinaron las láminas bajo el microscopio óptico.

Pruebas de susceptibilidad. Se obtuvieron crecimientos bacterianos a partir de las cepas aisladas y de la cepa control en caldo nutritivo, durante 24 h a $37^{\circ} \mathrm{C}$, en anaerobiosis. Una vez que alcanzaron una concentración de $0,5 \mathrm{Mac}$ Farland $\left(10^{8} \mathrm{UFC} / \mathrm{mL}\right)$, fueron inoculados en las placas de agar Mitis Salivarius, con un hisopo estéril, en tres direcciones diferentes, para permitir un crecimiento en césped, siguiendo las recomendaciones del método de difusión en disco para los antibiogramas.

Una vez inoculado el medio, se colocaron discos de papel de filtro, previamente impregnados con $20 \mu \mathrm{L}$ de cada extracto, así como del control negativo y positivo. Como control positivo se utilizó penicilina benzatínica (2 $400000 \mathrm{UI})(7 \mu \mathrm{L})$ y como control negativo solución salina $(20 \mu \mathrm{L})$.

Las placas se incubaron a $37^{\circ} \mathrm{C}$, durante 48 horas, en anaerobiosis. Los resultados fueron evaluados mediante la medición en milímetros de los diámetros del halo de inhibición del crecimiento de los microorganismos. El cálculo del porcentaje del efecto inhibitorio relativo respecto al control positivo, fue realizado de la siguiente forma ${ }^{13}$ :

$\%$ de inhibición = (Diámetro del halo de inhibición $/$ Diámetro del halo del control positivo) x 100

Análisis de datos. El análisis de los datos se fundamentó en la estadística descriptiva, utilizando medidas de tendencia central y de dispersión (media, mediana, desviación típica) en el caso de variables continuas; análisis de frecuencia y tablas de contingencia en el caso de variables discretas. Se realizó un análisis de varianza entre los grupos de cada especie de guayaba, con respecto al control positivo. Para comparar entre cáscaras verdes y maduras de cada especie, se realizó una prueba t de Student. Valores de $p<0,05$ fueron considerados estadísticamente significativos.

\section{Resultados}

En total se incluyeron tres pacientes pediátricos, con 5 , 7 y 8 ańos de edad. Del material recolectado de las cavidades de caries dental de cada uno de ellos, en dos de los pacientes se observaron colonias redondas, lisas en agar Mitis Salivarius, y en el tercer paciente se observaron colonias azules, rugosas. En agar Sangre las colonias fueron redondas sin halo de hemólisis en todos los casos. Se realizaron las coloraciones de Gram, las cuales mostraron colonias con forma de cocos, de color morado, indicando que pertenecen al grupo de bacterias Gram positivas. En base a estos resultados, se identificó $S$. mutans en el 
paciente 1 (P1), por lo que las pruebas de sensibilidad se realizaron con la cepa control y la cepa de P1 (Tabla 1).

Una vez realizados los extractos vegetales, a partir de las dos especies de guayaba, se realizaron las pruebas de sensibilidad in vitro, frente a cepas de $S$. mutans, tanto control, como aislada de pacientes.

Pruebas de susceptibilidad. Los resultados obtenidos demuestran que $S$. mutans fue sensible al extracto de las cáscaras de $P$. guajava en estadio verde, tanto para la cepa control, como para la cepa del paciente, observándose el mayor halo para $S$. mutans ATCC $25175(25 \mathrm{~mm})$ (Tabla 2).

Una vez obtenidos los halos, se calculó el porcentaje de inhibición de cada uno de los extractos, los cuales se muestran en la tabla 3, siendo el extracto de la especie P. guajava, en estadio verde, el que se obtuvo en mayor cantidad $(62,5 \%)$ para la cepa control, encontrando diferencias estadísticamente significativas entre $P$. guavaja y el control positivo $(\mathrm{p}=0,031)$, y $P$. acutangulum y el control positivo $(\mathrm{p}<0,001)$ (Tabla 3). Al sacar el pro- medio del efecto inhibitorio de cada extracto frente a las cepas, se obtuvo que para $P$. guajava verde fue de $43,8 \%$, P. guajava madura $22,5 \%$, P. acutangulum verde $27,5 \%$ y $P$. acutangulum madura $25,0 \%$.

Al comparar la acción de los extractos entre verde y maduro, se encontraron diferencias estadísticamente significativas entre $P$. acutangulum verde y madura con el control positivo, mas nos entre ambos estadios (Tabla 4). De igual forma se encontraron diferencias estadísticamente significativas entre $P$. guavaja verde y el control positivo (Tabla 5).

\section{Discusión}

Streptococcus mutans se considera uno de los principales microorganismos asociado al desarrollo de la caries dental, debido a su capacidad de degradar azúcares y descender el $\mathrm{pH}$ por la producción de ácidos a través de su metabolismo ${ }^{14}$. La caries dental está catalogada como la enfermedad bucal de mayor prevalencia a nivel internacional, presentando una alta proporción de individuos afectados en países con altos índices de pobreza ${ }^{2}$.

Tabla 1. Identificación de los aislados microbiológicos a partir de las muestras de caries cavitadas de pacientes pediátricos

\begin{tabular}{lccc}
\hline & Edad & Tinción de Gram & Identificación \\
\hline Cepa control & - & Cocos, morados & S. mutans ATCC 25175 \\
P1 & 7 años & Cocos, morados & S. mutans \\
P2 & 8 años & Cocos, morados & Streptococcus spp. \\
P3 & 5 años & Cocos, morados & Streptococcus spp. \\
\hline
\end{tabular}

P: paciente

Tabla 2. Diámetro del halo de inhibición de los extractos de guayaba y controles positivo y negativo frente a S. mutans ATCC 25175 y S. mutans paciente

\begin{tabular}{|c|c|c|c|}
\hline & & \multicolumn{2}{|c|}{ Halos de inhibición (mm) } \\
\hline & & $\begin{array}{c}\text { S. mutans ATCC } \\
25175\end{array}$ & $\begin{array}{l}\text { S. mutans } \\
\text { Paciente }\end{array}$ \\
\hline \multirow{2}{*}{ Extracto $P \cdot g u a j a v a$} & Verde & 25 & 10 \\
\hline & Madura & 8 & 10 \\
\hline \multirow{2}{*}{ Extracto P. acutangulum } & Verde & 10 & 8 \\
\hline & Madura & 7 & 9 \\
\hline Control positivo (Antibiótico) & & 40 & 35 \\
\hline Control negativo (Solución salina) & & 0 & 0 \\
\hline
\end{tabular}

Tabla 3. Porcentajes de inhibición de los extractos de guayaba frente a S. mutans ATCC 25175 y S. mutans paciente

\begin{tabular}{lccc}
\hline Extractos & $\begin{array}{c}\text { Inhibición (\%) } \\
\text { S. mutans ATCC 25175 }\end{array}$ & $\begin{array}{c}\text { Inhibición (\%) } \\
\text { S. mutans paciente }\end{array}$ & $\begin{array}{c}\text { ANOVA } \\
(\mathbf{p}<0,05)\end{array}$ \\
\hline P.guajava (V) & 62,5 & 25 & 0,031 \\
P.guajava (M) & 28,5 & 26,6 & $<0,001$ \\
P. acutangulum (V) & 20 & 25 & \\
P. acutangulum $(\mathbf{M})$ & 20 & 30 & \\
C (+) ANTB & 100 & 100 & - \\
C (-) S.S. & - & - & \\
\hline
\end{tabular}

V: verde; M: maduro; C: control; ANTB: antibiótico; S.S: solución salina 
Tabla 4. Comparación de la inhibición de los extractos de $P$. acutangulum verde y maduro, frente a las cepas de $S$. mutans

\begin{tabular}{lccc}
\hline & P. acutangulum $(\mathrm{V})$ & P.acutangulum $(\mathrm{M})$ & $\mathrm{C}+$ \\
\hline P. acutangulum $(\mathrm{V})$ & - & 0,666 & $0,004^{*}$ \\
P. acutangulum $(\mathrm{M})$ & 0,666 & - & $<0,001^{*}$ \\
$\mathrm{C}+$ & $0,004^{*}$ & $<0,001^{*}$ & - \\
\hline
\end{tabular}

${ }^{*} p<0,005 ; C+$ : Control positivo

Tabla 5. Comparación de la inhibición de los extractos de $P$. guajava verde y maduro, frente a las cepas de $S$. mutans

\begin{tabular}{lccc}
\hline & $P . g u a j a v a(\mathrm{~V})$ & P.guajava $(\mathrm{M})$ & $\mathrm{C}+$ \\
\hline P.guajava (V) & - & 0,378 & $0,001^{*}$ \\
$P$. guajava (M) & 0,378 & - & 0,095 \\
$\mathrm{C}+$ & $0,001^{*}$ & 0,095 & - \\
\hline
\end{tabular}

$* p<0,05 ; C+:$ Control positivo

En Venezuela, un reporte sobre caries en dentición permanente, indica que existe una relación proporcional entre el porcentaje de personas con esta lesión y el aumento de la edad del paciente. De la población infantil estudiada se observó que en el grupo de 7 años de edad, $37 \%$ de los niños presentaban caries en los dientes permanentes, sobre todo en el sexo femenino (56\%); en el grupo de 12 años, la proporción se elevaba a $83 \%$ de pacientes enfermos; en el grupo de 18 años, a 96\%; y en el de 25 años y más, a 99\%. De igual forma, determinaron que el promedio de dientes afectados por caries a los 7 años fue de 0,8 y a los 12 de 3,7, indicando un incremento de piezas dentarias involucradas, en relación con la edad ${ }^{5}$. Esto refleja la importancia epidemiológica de dicho padecimiento y a su vez, también manifiesta la necesidad de buscar métodos alternativos para su tratamiento que busquen reducir costos y representen opciones seguras para los pacientes afectados con la condición.

En el presente estudio, una vez realizada la experimentación en el laboratorio, se pudo determinar que el extracto de las especies de guayabas utilizadas produce la inhibición de $S$. mutans, corroborado por la formación de halos de inhibición alrededor de los discos con los diferentes extractos de guayaba, siendo este, para nuestro conocimiento, el primer trabajo realizado en el país.

Vale la pena señalar, que a pesar que se observa inhibición, esta no logró alcanzar la generada por el control positivo, correspondiente a la penicilina benzatínica, que en promedio tuvo una inhibición del $100 \%$ de la cepa de S. mutans.

$\mathrm{Al}$ evaluar la inhibición de cada especie de guayaba, el estudio permitió observar como la especie $P$. guajava, en su estadio verde, mostró el mayor porcentaje frente a la especie de $S$. mutans, tanto para la cepa control, como la aislada del paciente, con $43,8 \%$ en promedio. Si comparamos con el trabajo realizado por Neira y Ramírez ${ }^{8}$ en el 2005, su porcentaje de inhibición fue mucho mayor, pero igualmente, fue obtenido con la cáscara de la guayaba en estadio verde, con un 70,83\%. La diferencia entre los valores obtenidos, podría deberse a la metodología utilizada para la obtención de los extractos, ya que estos autores utilizan un protocolo distinto al realizado en este trabajo, pudiendo obtener un mejor rendimiento. Sin embargo, corroboramos que el extracto de guayaba $P$. guajava en estadio verde, tiene actividad antimicrobiana frente a cepas de $S$. mutans. Prabu et al. ${ }^{15}$ indican que los flavonoides activos de la guayaba muestran un alto potencial como agentes antimicrobianos, específicamente inhibiendo el crecimiento de $S$. mutans.

Considerando estos resultados, se puede concluir que los extractos de la especie $P$. guajava tienen efecto antimicrobiano sobre $S$. mutans, representando una opción terapéutica frente a este microorganismo, siendo una posible herramienta complementaria para la prevención de la caries dental, mediante la preparación de productos como enjuagues bucales.

\section{Referencias bibliográficas}

1. Ojeda J, Oviedo E, Salas A. Streptococcus mutans y caries dental. CES Odontol. 2013;26(1):44-56.

2. Tsang P, Qi F, Shi W. Medical Approach to Dental Caries: Fight the disease, not the lesion. Pediatr Dent. 2006;28(2):188-191.

3. Rojas F. Algunas consideraciones sobre caries dental, fluoruros, su metabolismo y mecanismos de acción. Acta Odontol Ven. 2008;46(4):509-516.

4. Hamada S, Slade H. Biology, immunology, and cariogenicity of Streptococcus mutans. Microbiol Rev. 1980;44(2):331-384.

5. Organización Panamericana de la Salud (OPS). Odontología preventiva no convencional. Programa de Educación Continuada Odontológica. 2000. [Consultado del 15 de Febrero 2017]. Accesible en: http://bvs.sld.cu/ revistas/san/vol13_5_09/san12509.htm

6. Rivero M, Álvarez M, López T, González J. Actividad antifúngica in vitro de Pinus caribaea. Rev Cubana de Plant Med. 1997;2(1):25-29. 
7. Maritza R. Plantas medicinales y flores ornamentales. Guayaba. 2016. [Consultado del 22 de Febrero 2017]. Accesible en: http://mary55.cubava.cu/2016/11/05/guayaba/

8. Neira A, Ramírez M. Actividad antibacteriana de extractos dos especies de guayaba contra Streptococcus mutans y Escherichia coli. Actual Biol. 2005;27(1):27-30.

9. Biswas B, Rogers K, McLaughlin F, Daniels D, Yadav A. Antimicrobial activities of leaf extracts of Guava (Psidium guajava L.) on two Gram-negative and Gram-positive bacteria. Int J Microbiol. 2013:1-7. doi: $10.1155 / 2013 / 746165$.

10. Razak A, Rahim Z. The anti-adherence effect of Piper beetle and Psidium guajava extracts on the adhesion of early settlers in dental plaque to saliva-coated glass surfaces. J Oral Sci. 2003;45(4):201-206. doi: 10.2334/ josnusd.45.201

11. Nelce M, Mahendradatta M, Laga A, Djide N. Antimicrobial Activities of Tannins Extract From Guajava
Leaves (Psidium guajava L.) on Pathogens Microbial. Int J Scien Tech Res. 2014;3(1):236-241.

12. Limsong J, Benjavongkulchai E, Kuvatanasuchati J. Inhibitory effect of some herbal extracts on adherence of Streptococcus mutans. J Ethnopharmacology. 2004;92281-289. doi:10.1016/j.jep.2004.03.008.

13. Martínez M, Molina N, Boucourt E. Evaluación de la actividad antimicrobina del Psidium Guajava L. Rev Cubana de Plant Med. 1997;2(1):12-14.

14. Nogueira M, Díaz M, Tagami P, Lorscheide J. Atividade antimicrobiana de óleos essenciais e extratos de própolis sobre bacterias cariogênicas. Rev Ciênc Farm Básica Apl. 2007;28(1):93-97.

15. Prabu G, Gnanamani A, Sadulla S. Guaijaverin-a plant flavonoid as potential antiplaque agent against Streptococcus mutans. J App Microbiol. 2006;101:487-495. doi:10.1111/j.1365-2672.2006.02912.x. 